\title{
A Comparison of Arterial and Venous Blood Gas Analysis and Its Interpretation in Emergency Department: A Cross-Sectional Study
}

\author{
(1) Ram Kirubakar Thangaraj, (1) Hari Hara Sudhan Chidambaram, (1) Melvin Dominic, (1) V.P. Chandrasekaran, \\ (1) Karthik Narayan Padmanabhan, (1) K.S. Chanjal
}

Department of Emergency Medicine, Vinayaka Mission Kirupananda Variyar Medical College \& Hospital, Tamil, Nadu, India

\begin{abstract}
Aim: This study aimed to determine the agreement between arterial blood gas (ABG) and venous blood gas (VBG) analyses in a pathologically diverse patient population who presented to the emergency department.

Materials and Methods: This cross-sectional study was conducted in the emergency department of a tertiary care hospital during the period from February 2019 to June 2020. A total of 113 patients presenting with various medical conditions confirmed on ABG by a physician were recruited. Both arterial and venous blood samples were collected for blood gas analysis. Using a Bland-Altman plot, data obtained were analyzed for agreement. IBM SPSS version 22 was used for the data analysis.

Results: Among the 113 study participants, the arterial and venous $\mathrm{pH}$ values, base excess, and bicarbonate level show acceptably narrow $95 \%$ limits of agreement in the Bland-Altman plot $(-0.06$ to $0.08,-4.08$ to 2.30 , and -2.59 to 0.89 , respectively). Agreement in partial pressure of oxygen and oxygen saturation measurements was poor (95\% limits of agreement, -8.38 to 101.06 and 0.35 to 0.58 , respectively). Agreement of partial pressure of carbon dioxide shows an acceptably narrow agreement (95\% limits of agreement, -10.61 to -2.18 ).

Conclusion: VBG analysis for $\mathrm{pH}$, bicarbonate, and base excess may be a reliable substitute for ABG analysis in the initial evaluation of adult patients presenting to the emergency department.
\end{abstract}

Keywords: Blood gas analysis, venous blood gas analysis, venous and arterial blood sampling, agreement

\section{Introduction}

In emergency departments and intensive care, the routinely performed procedure is arterial blood gas analysis (ABG) (1). ABG is the gold standard procedure to know about the acid-base balance, oxygenation and ventilation-perfusion in patients in critical care treatment (2). Arterial blood gas analysis requires a sample of arterial blood, which is obtained mostly from radial or femoral arteries. The sampling requires deep puncture into one of the arteries, which can be painful to the patient. It may also lead to various complications like bleeding, hematoma formation, infection, embolism and formation of arterial aneurysm or in very severe cases compartment syndrome $(3,4)$. In intensive care settings, to assess the patient status, there is a need for repeated $A B G$ analysis. This can put the patient through painful needle punctures that can increase the chances of infection. The alternative to $A B G$ is venous blood gas analysis (VBG). In intensive care and patients presenting to the emergency department, venous sampling is more convenient and easy to perform (5). Few venepunctures are required, thereby reducing the risk of needle stick injury to the health care professionals.

Acid-base balance measured through blood gas analysis plays a critical role in the planning of the course of treatment. The 
assessment is done in an arterial blood sample. In routine practice, the sampling results in the mixed sample or venous sample (6); this can cause detrimental effects in the diagnosis and treatment plan. Pulse oximetry measurements of arterial oxygen saturation draw a parallel to oxygen saturation as measured by $\mathrm{ABG}$, and transcutaneous carbon dioxide tension can provide a useful guide to the adequacy of ventilation (7). The values of $\mathrm{pH}$, bicarbonate, and carbon dioxide tension can be measured in arterial as well as venous blood gas analysis.

Various studies in the past have suggested that venous blood gas analysis can be considered as an alternate to the arterial blood gas analysis, VBG still has not gained much acceptance among clinicians (8-12). A study by Kelly et al. (8). has shown that venous bicarbonate estimation had a high level of agreement with the arterial value, with acceptably narrow 95\% limits of agreement. A study by Ma et al. (10) proved that ABG results rarely influenced emergency physicians' decisions on diagnosis, treatment, or disposition in suspected diabetic ketoacidosis (DKA) patients. The usability of VBG in acid base status is still under research. The previous researchers suggested that VBG in place of $A B G$ is sufficient to make clinical decisions. There is a lacuna in literature corresponding to the place of this current study. So, to add on to the available evidence and to study the pattern this current study was done. This present study was carried out to determine the agreement between ABG and VBG in a pathologically diverse patient population presenting to the emergency department of a tertiary care hospital.

\section{Materials and Methods}

A cross-sectional study was conducted at the emergency department and critical care units of VMKV Medical College Hospital, Salem during February 2019 - June 2020. The study was approved by the institutional ethical committee of VMKV Medical College Hospital, Salem. Informed written consent was obtained from all participants, and data confidentiality was maintained. For critically ill patients and those who were unconscious during the study, the consent was obtained from the attenders. All patients needing ABG as per clinician advised were recruited into the study. For the recruitment of the participants, convenience sampling was followed. All patients above the age of 18 were presenting to the emergency department and all patients requiring $A B G$ for their treatment after initial emergency residence (ER) assessment were included in the study. Patients on anticoagulant therapy, Patients with bleeding disorders, patients with peripheral vascular disease/compartment syndrome and those Patients with arterial thrombosis were excluded from the study.

\section{Methodology}

After obtaining informed consent, detailed history and clinical examination were done for all patients. The need for ABG was assessed, and both arterial and venous samples were obtained within 2 minutes of each other. Both ABG and VBG were analysed in the same blood gas analyser (ABBOTT ABG POC analyser). The arterial blood was drawn from the radial or femoral arterythe venous blood from a peripheral vein and blood for other investigations. The blood samples were obtained in strict aseptic precautions in a pre-heparinised syringe and transported in the cold chain to the laboratory immediately. The ABG and VBG values were interpreted, and the data were compared.

\section{Sample Size Calculation}

The sample size was calculated assuming the expected mean difference of $\mathrm{pCO}_{2}$ between $\mathrm{ABG}$ and $\mathrm{VBG}$ methods as three and standard deviation as 1.2 as per the study by Malatesha et al. (1) 26 females, mean; the maximum allowed difference $\mathrm{pCO}_{2}$ between two methods was considered as 6 . The other parameters considered for the sample size calculation included $5 \%$ alpha error and $80 \%$ power of the study.

The required sample size as per the calculation mentioned above was 86 . To account for the non-participation rate/absence of about $20 \%$, another 18 subjects will be added to the sample. Hence the final required sample size was 104 subjects. For better representation and availability, 113 subjects were considered in the final study.

Sample size calculation was done using Medcalc software (13).

\section{Statistical Analysis}

$\mathrm{pH}, \mathrm{HCO}_{3}$, base excess, $\mathrm{pCO}_{2}$ and $\mathrm{SpO}_{2}$ in $\mathrm{ABG}$ and $\mathrm{VBG}$ methods were considered as the primary outcome variables. Two procedures ABG vs VBG was considered as explanatory variable. Descriptive analysis was carried out by mean and standard deviation for quantitative variables, frequency and proportion for categorical variables. All quantitative variables were checked for normal distribution within each category of explanatory variable by using visual inspection of histograms and normality Q-Q plots. Shapiro-Wilk test was also conducted to assess normal distribution. Shapiro-Wilk test $p$-value of $>0.05$ was considered as normal distribution. Bland-Altmann plot $95 \%$ confidence interval (Cl) was used to know the agreement of different parameters between ABG and VBG methods. The association between non-normal quantitative outcome was assessed by comparing the median values. Wilcoxon signed test was used to assess statistical significance. 
p-value $<0.05$ was considered statistically significant. IBM SPSS version 22 was used for statistical analysis (14).

\section{Results}

A total of 113 subjects were included in the final analysis. The mean age was 50.73 years in the study population. Among the study population, majority were male as 73 (64.60\%). The mean systolic blood pressure was 120 ( $\mathrm{mmHg}$ ) in the study population. The mean diastolic blood pressure was $80.09(\mathrm{mmHg})$ in the study population. The mean pulse rate was 89.66 (bpm) in the study population. The mean oxygen saturation was $0.92 \%$ in the study population. The mean respiratory rate (per min) was 25.81 in the study population (Table 1).

The mean difference of the $\mathrm{pH}$ between the two methods was 0.01 , with $95 \% \mathrm{Cl}$ ranging from $(-0.06$ to 0.08$)$. The mean difference of the $\mathrm{pCO}_{2}$ between the two methods was -6.4 with $95 \% \mathrm{Cl}$ ranging from (-10.61 to -2.18$)$. The mean difference of the $\mathrm{HCO}_{3}$ between the two methods was -0.85 with $95 \% \mathrm{Cl}$ ranging from ( -2.59 to 0.89$)$. The mean difference of the Base excess between the two methods was -0.89 with $95 \% \mathrm{Cl}$ ranging from

\begin{tabular}{|l|l|}
\hline \multicolumn{2}{|l|}{ Table 1. Summary of baseline parameter (n=113) } \\
\hline Parameter & Summary \\
\hline Age, (mean \pm SD) (years) & $50.73 \pm 14.74$ (range: 20 to 82$)$ \\
\hline Gender & $73(64.60 \%)$ \\
\hline Male & $40(35.40 \%)$ \\
\hline Female & \multicolumn{2}{|l|}{} \\
\hline Vital signs, (mean \pm SD) & $120 \pm 25.77$ (range: 60 to 210$)$ \\
\hline Systolic blood pressure, $(\mathrm{mmHg})$ & $80.09 \pm 60.57$ (range: 40 to 700$)$ \\
\hline Diastolic blood pressure, (mmHg) & $89.66 \pm 16.73$ (range: 62 to 162) \\
\hline Pulse, (bpm) & $0.92 \pm 0.06$ (range: 0.7 to 1) \\
\hline Oxygen saturation, (\%) & $25.81 \pm 4.93$ (range: 14 to 38) \\
\hline Respiratory rate, (per min) & \\
\hline SD: Standard deviation, n: Number &
\end{tabular}

(-4.08 to 2.30). The mean difference of the $\mathrm{PO}_{2}$ between the two methods was 46.34 , with $95 \% \mathrm{Cl}$ ranging from (-8.38 to 101.6). The mean difference of the oxygen saturation between the two methods was 0.47 , with $95 \% \mathrm{Cl}$ ranging from (0.35 to 0.58 ) (Table 2). Bland Altmann plots depicting the difference in arterial and venous $\mathrm{pH}$ and $\mathrm{pCO}_{2}$ measurements between average of arterial and venous $\mathrm{pH}$ and $\mathrm{pCO}_{2}$ is represented in Figures 1 and 2.

\section{Discussion}

The study findings showed acceptable agreement between ABG and VBG analysis among the study participants. In literature, there is plenty of evidence for the agreement between $A B G$ and VBG (8,10-12,15). Despite the available evidence in the literature, VBG has not gained confidence for routine usage among the clinicians. Few studies in the past have expressed reservations on the diagnostic accuracy of VBG inaccurate patient evaluation $(12,16,17)$.

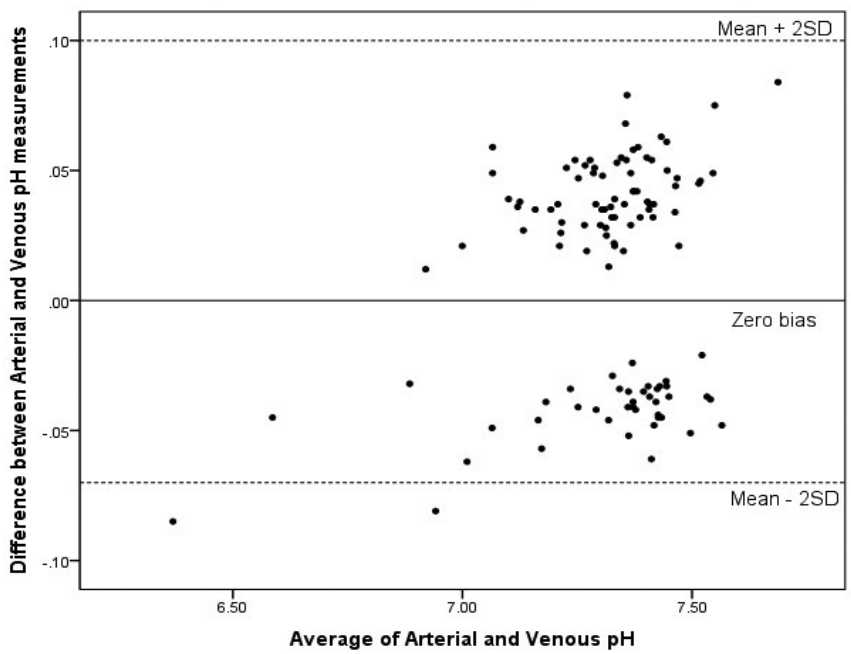

Figure 1. Bland-Altmann plots of difference in arterial and venous $\mathrm{pH}$ measurements between average of arterial and venous $\mathrm{pH}$

SD: Standard deviation

Table 2. Mean difference in lab parameter between two methods $(n=113)$

\begin{tabular}{|c|c|c|c|c|c|}
\hline \multirow[t]{2}{*}{ Parameter } & \multirow[t]{2}{*}{$\begin{array}{l}\mathrm{ABG} \\
(\text { Mean } \pm \mathrm{SD})\end{array}$} & \multirow[t]{2}{*}{$\begin{array}{l}\text { VBG } \\
(\text { Mean } \pm \text { SD) }\end{array}$} & \multirow[t]{2}{*}{$\begin{array}{l}\text { Difference } \\
\text { (Mean } \pm \text { SD) }\end{array}$} & \multicolumn{2}{|c|}{$\begin{array}{l}\text { Bland-Altman } \\
(95 \% \mathrm{CI})\end{array}$} \\
\hline & & & & Lower & Upper \\
\hline $\mathrm{PCO}_{2}(\mathrm{mmHg})$ & $41.98 \pm 16.36$ & $48.38 \pm 16.42$ & $-6.4 \pm 2.15$ & -10.61 & -2.18 \\
\hline $\mathrm{HCO}_{3}(\mathrm{mmol} / \mathrm{L})$ & $21.31 \pm 8.78$ & $22.16 \pm 8.59$ & $-0.85 \pm 0.89$ & -2.59 & 0.89 \\
\hline $\mathrm{PO}_{2}(\mathrm{mmHg})$ & $87.31 \pm 38.83$ & $40.97 \pm 14.84$ & $46.34 \pm 27.92$ & -8.38 & 101.06 \\
\hline Oxygen saturation & $0.93 \pm 0.06$ & $0.45 \pm 0.06$ & $0.47 \pm 0.06$ & 0.35 & 0.58 \\
\hline
\end{tabular}




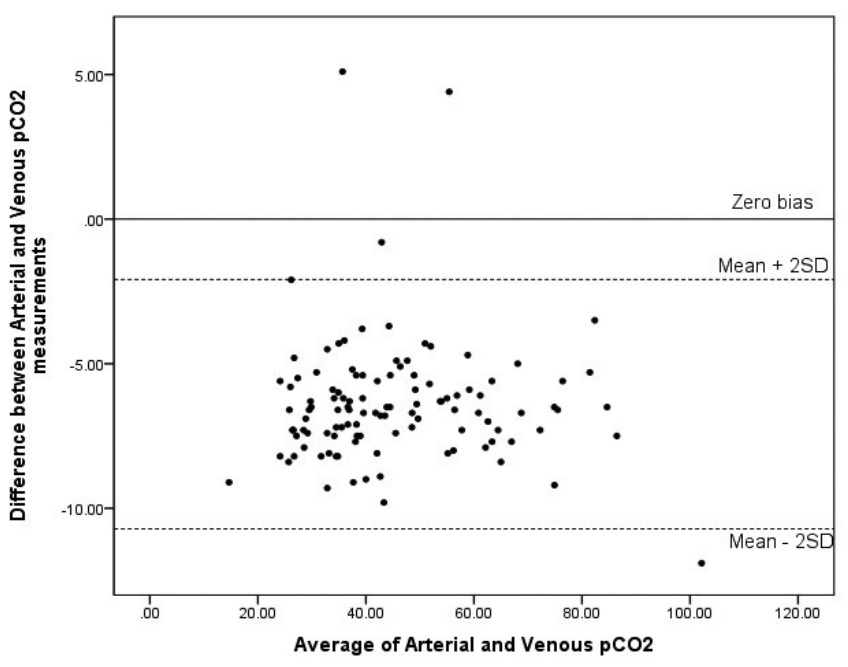

Figure 2. Bland-Altmann plots of difference in arterial and venous $\mathrm{pCO}_{2}$ measurements between average of arterial and venous $\mathrm{pCO}_{2}$

This present study was carried out to evaluate whether VBG can replace $A B G$ in initial patient evaluation in emergency departments. As shown in results, the agreement is excellent with $95 \%$ limits of agreement as -0.06 to $0.08 \mathrm{in} \mathrm{pH}$. In this present study, the agreement in $\mathrm{pCO}_{2}$ and bicarbonate values show an acceptably narrow agreement compared to the previous study (12).

Agreement of $\mathrm{pCO}_{2}$ in previous studies is good and within acceptably narrow limits, but in this particular study even though $\mathrm{pCO}_{2}$ shows an acceptably narrow agreement $(95 \%$ limits of agreement -10.61 to -2.18 ) since the zero bias is outside the limit. This indicates there is a significant difference between arterial and venous measurements. Hence the arterial and venous $\mathrm{pCO}_{2}$ values cannot be replaced with each other.

As expected, the venous $\mathrm{pO}_{2}$ and arterial $\mathrm{pO}_{2}$ did not show good agreement in our study (95\% limits of agreement -8.38 to 101.06), as the difference is too great to be clinically significant.

The mean difference of the $\mathrm{HCO}_{3}$ between the two methods was -0.85 with $95 \% \mathrm{Cl}$ ranging from $(-2.59$ to 0.89$)$. The mean difference of the Base excess between the two methods was -0.89 with $95 \% \mathrm{Cl}$ ranging from ( -4.08 to 2.30 ). Both these parameters suggest agreement between ABG and VBG.

Among the previous available literature, the most commonly studied group of participants were a single diseased group like DKA and renal failure $(10,11)$. In this study, only a few patients in the study group had extremes of $\mathrm{pPH}$ and were in shock; therefore, it was not possible to find the agreement and correlation of ABG and VBG values in those patients. Hence a more extensive study of patients in the extremes of $\mathrm{pH}$ and states of shock is needed to comment on the agreement and correlation of patients in those states.

The strength of this study being, the study was conducted among the wide array of patients attending the emergency department. The limitation of the current study was the recruitment of the participants were not done randomly, and convenience sampling was followed.

\section{Conclusion}

Thus, we can conclude from my study that $\mathrm{pH}, \mathrm{HCO}_{3}$ and Base Excess agree well in $A B G$ and $V B G$ analysis, and both can be used interchangeably in the ER. We recommend that Based on the initial assessment of patients in the ER, VBG can be used as an alternative for $A B G$ as it will not alter the treatment of the patient drastically.

\section{Acknowledgements}

We acknowledge the technical support in data entry, analysis and manuscript editing by "Evidencian Research Associates."

\section{Ethics}

Ethics Committee Approval: Ethics Committee approval was taken before initiating the study from Vinayaka Mission's Kirupananda Variyar Medical College, Ethics Committee (number: VMKVMC\&H/IEC/19/48, on 06.03.2019).

Informed Consent: Informed written consent was obtained from all participants, and data confidentiality was maintained.

Peer-review: Externally peer-reviewed.

\section{Authorship Contributions}

Surgical and Medical Practices: R.K.T., Concept: R.K.T., H.H.S.C., Design: R.K.T., H.H.S.C., M.D., Data Collection or Processing: R.K.T., M.D., K.N.P., Analysis or Interpretation: R.K.T., H.H.S.C., M.D., V.P.C., Literature Search: R.K.T., V.P.C., K.S.C., Writing: R.K.T., K.S.C.

Conflict of Interest: No conflict of interest was declared by the authors.

Financial Disclosure: The project was self-funded. No external agency had funded the project.

\section{References}

1. Malatesha G, Singh NK, Bharija A, Rehani B, Goel A. Comparison of arterial and venous pH, bicarbonate, $\mathrm{PCO} 2$ and $\mathrm{PO} 2$ in initial emergency department assessment. Emerg Med J. 2007;24:569-71.

2. Ziegenfuß T, Zander R. Understanding blood gas analysis. Intensive Care Med. 2019;45:1684-5.

3. Mortensen JD. Clinical sequelae from arterial needle puncture, cannulation, and incision. Circulation. 1967;35:1118-23. 
4. Bisarya K, George S, El Sallakh S. CASE REPORT Acute Compartment Syndrome of the Forearm Following Blood Gas Analysis Postthrombolysis for Pulmonary Embolism. Eplasty. 2013;13:e15.

5. Razi E, Nasiri O, Akbari H, Razi A. Correlation of arterial blood gas measurements with venous blood gas values in mechanically ventilated patients. Tanaffos. 2012;11:30-5.

6. O'Connor TM, Barry PJ, Jahangir A, Finn C, Buckley BM, El-Gammal A. Comparison of arterial and venous blood gases and the effects of analysis delay and air contamination on arterial samples in patients with chronic obstructive pulmonary disease and healthy controls. Respiration. 2011;81:18-25.

7. Jensen LA, Onyskiw JE, Prasad NG. Meta-analysis of arterial oxygen saturation monitoring by pulse oximetry in adults. Heart Lung. 1998;27:387-408.

8. Kelly AM, McAlpine R, Kyle E. Agreement between bicarbonate measured on arterial and venous blood gases. Emerg Med Australas. 2004;16:407-9.

9. Kelly AM, McAlpine R, Kyle E. Venous pH can safely replace arterial pH in the initial evaluation of patients in the emergency department. Emerg Med J. 2001;18:340-2.

10. Ma OJ, Rush MD, Godfrey MM, Gaddis G. Arterial blood gas results rarely influence emergency physician management of patients with suspected diabetic ketoacidosis. Acad Emerg Med. 2003;10:836-41.
11. Gokel Y, Paydas S, Koseoglu Z, Alparslan N, Seydaoglu G. Comparison of blood gas and acid-base measurements in arterial and venous blood samples in patients with uremic acidosis and diabetic ketoacidosis in the emergency room. Am J Nephrol. $2000 ; 20: 319-23$.

12. Kelly AM, Kyle E, McAlpine R. Venous pCO(2) and pH can be used to screen for significant hypercarbia in emergency patients with acute respiratory disease. J Emerg Med. 2002;22:15-9.

13. Simsek FS, Balci TA, Dönder Y, Ugur K, Kilinc F, Cetinkaya Z, et al. The importance in diagnosing patients with conflicting observational data for post surgery radioiodinated ablation of thyroid remnants. Hell J Nucl Med. 2019;22:58-63.

14. Armonk NIC. IBM Corp. IBM SPSS Statistics for Windows, Version 22.0. 2013.

15. Middleton P, Kelly AM, Brown J, Robertson M. Agreement between arterial and central venous values for $\mathrm{pH}$, bicarbonate, base excess, and lactate. Emerg Med J. 2006;23:622-4.

16. Brashear RE, Oei TO, Rhodes ML, Futty DE, Hostetler ML. Relationship between arterial and venous bicarbonate values. Arch Intern Med. 1979;139:440-2.

17. Dries DJ. Correlation of Central Venous and Arterial Blood Gas Measurements in Mechanically Ventilated Trauma Patients. Yearb Crit Care Med. 2007; 2007:87-8. 